\title{
Formulation and Characterization of Sinterless Barium Strontium Titanate (BST) Dielectric Nanoparticle Ink for Printed RF and Microwave Applications
}

\author{
Oshadha K. Ranasingha ${ }^{1}\left[\right.$ ( Mahdi Haghzadeh ${ }^{1} \cdot$ Margaret J. Sobkowicz $^{2} \cdot$ Edward Kingsley $^{1} \cdot$ Craig Armiento $^{1}$. \\ Alkim Akyurtlu ${ }^{1}$
}

Received: 14 December 2020 / Accepted: 27 March 2021 / Published online: 21 April 2021

(c) The Minerals, Metals \& Materials Society 2021

\begin{abstract}
Here, we report a previously unreported low-temperature curable barium strontium titanate $\left(\mathrm{Ba}_{\mathrm{X}} \mathrm{Sr}_{1-\mathrm{X}} \mathrm{TiO}_{3}\right)$ or BST dielectric nanoparticle ink which shows a high dielectric tunability for printed electronics/additive manufacturing applications. The newly formulated BST ink is optimized to print in aerosol jet printers and can be cured at $150^{\circ} \mathrm{C}$, which will allow the fabrication of tunable radio-frequency (RF) and microwave (MW) devices on a wide range of flexible substrates. Characterization of high-frequency dielectric properties showed a high dielectric tunability $(\sim 15 \%$ at $10 \mathrm{GHz}$ with $10 \mathrm{~V} / \mu \mathrm{m})$ and a high dielectric constant $(\sim 16$ at $10 \mathrm{GHz})$. The linear-reversible tunability, which is very important for tunable devices, was confirmed by the tunability testing at $10 \mathrm{GHz}$. Characterization of temperature-dependent dielectric properties found $<10 \%$ variations of the dielectric constant at $10 \mathrm{GHz}$ from $-50^{\circ} \mathrm{C}$ to $125^{\circ} \mathrm{C}$ for this BST ink. Detailed information on BST nanoparticle characterization, ink formulation and characterization of dielectric properties is discussed.
\end{abstract}

Keywords Printed electronics $\cdot$ printable BST ink $\cdot$ tunable dielectrics $\cdot$ aerosol jet printing $\cdot$ additive manufacturing

\section{Introduction}

Tunable radio-frequency (RF) and microwave devices play an important role in reconfigurable systems, and when combined with additive manufacturing and printed electronics, they can provide advantages in terms of cost, size and form factor. ${ }^{1-5}$ The demand for printable electronics over conventional electronics is rising exponentially due to the extremely low fabrication cost, low material consumption and wastage, compatibility with flexible substrates, durability and ease of customization.

Oshadha K. Ranasingha

Oshadha_Ranasingha@uml.edu

$\triangle$ Alkim Akyurtlu

Alkim_Akyurtlu@uml.edu

1 Printed Electronics Research Collaborative (PERC), Electrical and Computer Engineering Department, University of Massachusetts Lowell, 1 University Avenue, Lowell, MA 01854, USA

2 Plastics Engineering Department, University of Massachusetts Lowell, 1 University Avenue, Lowell, MA 01854, USA
Barium strontium titanate (BST) has been extensively investigated over the last few decades due to its tunable dielectric properties. ${ }^{6-18}$ The dielectric constant of BST can be tailored by an applied electric field, which allows BST to be used in varactors for tunable RF and microwave (MW) applications, such as tunable filters, phase shifters, frequency selective surfaces, phased arrays and conformal antennas. ${ }^{2,4,19-25}$ BST has a para-electric phase above the Curie temperature $\left(T_{C}\right)$ due to the cubic and symmetric crystal structure, with no spontaneous polarization. Below the Curie temperature, BST has a ferroelectric phase due to the spontaneous polarization of the non-center symmetric crystal structure. ${ }^{26,27}$ In the para-electric phase, BST shows the highest dielectric properties, such as high tunability, low loss tangent and high switching speed. ${ }^{28}$

Various techniques, such as pulsed laser deposition, chemical vapor deposition and sputtering are well-established deposition techniques for the fabrication of BSTbased electronic devices. ${ }^{17,29-33}$ However, all these techniques require high processing temperatures that are not suitable for flexible substrates and fabrics. Moreover, it is difficult to vary the highest effective dielectric constant in these deposition techniques. 
Different types of direct-write noncontact functional ink printers, such as inkjet printers, aerosol jet printers and dispensing printers, are widely used in printed electronics research and development as well as in small-scale manufacturing. ${ }^{34-44}$ Nonetheless, these printers have different specifications and limitations. For example, the viscosity of functional inks needs to be below $1000 \mathrm{cP}$ in order to be printed in Optomec aerosol jet printers with pneumatic atomization, while a viscosity of less than $10 \mathrm{cP}$ is necessary to be printed in Optomec aerosol jet printers with ultrasonic atomization. Therefore, printer-specific functional inks are very important for printed electronic device fabrication. Optomec aerosol jet printers can be used to print high-resolution features as low as $10 \mu \mathrm{m}$ with the best conditions. Also, the newest version of the Optomec AJ5X aerosol jet printer has the capability to print on any three-dimensional (3D) object using its five-axis ( $X, Y, Z$, rotation and tilting) motion. It is necessary to have a high-quality printable BST ink in order to get the advantage of this five-axis aerosol jet printers when printing electronic devices with small feature sizes. However, there is no previously reported stable BST ink for aerosol jet printers to print high-resolution tunable electronic devices.

Functional inks are one of the most important components in printed electronics fabrication since the performance of a printed electronic device depends greatly on the properties of the functional inks and the device design. Even though device design and optimization are widely explored areas, functional ink development is a relatively unexplored area, especially for aerosol jet printing. The RF properties, including the complex dielectric constant (real part and loss tangent) and the degree of tunability of a functional ink, must be optimized to achieve the highest possible performance of devices. In addition to electromagnetic properties, there are several factors that need to be considered when developing a functional ink, such as the stability of the ink without any nanoparticle agglomeration, decreased foaming, controllable printability, long shelf life, low curing temperature, higher adhesion and good wettability on a wide range of substrates and less toxicity. Also, the number of compatible printing technologies is another key factor to be considered at the commercialization stage.

In this work, we have formulated and optimized a sinterless BST nanoparticle ink for aerosol jet printers, which is suitable for the fabrication of RF and MW applications. This ink can be cured at $150^{\circ} \mathrm{C}$, and it does not need the sintering at a higher temperature. Spherical BST nanoparticles with a diameter of $\sim 80 \mathrm{~nm}$ were used in this ink. We have provided experimental evidence for previously unreported high dielectric tunability at $10 \mathrm{GHz}$ for this BST ink. In addition to that, it shows a high dielectric constant and low loss tangent in the 2-12-GHz frequency range. Most importantly, this BST ink can be processed at a relatively low temperature, which is suitable for most of the flexible and rigid substrates.

\section{Materials and Methods}

\section{List of Materials}

Barium strontium titanate $\left(\mathrm{Ba}_{0.67} \mathrm{Sr}_{0.33} \mathrm{TiO}_{3}\right)$ nanoparticles and ammonium polymethacrylate in water (commercial name - NanoSperse $S$ ) were purchased from TPL Inc. (New Mexico, USA). Ethylene glycol (99\%) was purchased from Fisher Scientific (USA). 1-Methoxy-2-propanol (99.5\%) was purchased from Sigma-Aldrich (USA). All the chemicals were used without further purification. Paru MicroPE PG-007 silver nanoparticle ink was purchased from Paru Co., Ltd. (South Korea). Different types of substrates that are suitable for RF and MW applications were tested with BST nanoparticle ink. RO3850, RO3035, RO5780 and liquid crystal polymer (LCP) substrates were purchased from Rogers Corporation (USA). Kapton general-purpose polyamide films were purchased from DuPont (USA).

\section{BST Ink Formulation, Printing and Curing Procedure}

BST nanoparticles (50 wt.\%) were added to ethylene glycol and sonicated for $8 \mathrm{~h}$ in the pulse mode (active $=15 \mathrm{~s}$, inactive $=59 \mathrm{~s}$ ) using a QSONICA Q500 ultrasonic processor with a 2-mm micro-tip. Then, ammonium polymethacrylate in water $(\sim 2 \mathrm{wt} . \%)$ was added into the mixture as a dispersant and sonicated for another $30 \mathrm{~min}$ in the pulse mode $($ active $=5 \mathrm{~s}$, inactive $=59 \mathrm{~s}$ ). This BST nanoparticle dispersion was used as a stock solution for the BST ink formulation. A custom-made BST nanoparticle dispersion in ethylene glycol, which had the exact same components and amounts, was directly purchased from TPL Inc.

In this work, the BST ink was formulated and optimized for aerosol jet printers. Ink was formulated by adding ethylene glycol (25 wt.\%) and 1-methoxy-2-propanol (25 wt.\%) to the previously prepared BST dispersion (stock solution), and the mixture was magnetically stirred overnight at $400 \mathrm{rpm}$ in order to obtain a homogenous ink. This ink was developed to print thin $(<10 \mu \mathrm{m})$ and smaller features $(<100$ $\mu \mathrm{m})$ in aerosol jet printers and to achieve a higher dielectric tunability and a non-varying dielectric constant at higher frequencies (2-12 GHz) with a low loss tangent. Optomec AJ200 and AJ5X aerosol jet printers with pneumatic atomizers were used to print the BST ink. A Fisher Scientific vacuum oven was used to cure the printed features at $150^{\circ} \mathrm{C}$ for 60 min under vacuum.

\section{Characterization Techniques}

An ARES-G2 rheometer (TA Instruments) was used to measure the viscosities of the ink. Ink samples were loaded 
in a 400-mm diameter, 0.04-rad stainless-steel cone and plate geometry. Flow sweeps from $1 \mathrm{~s}^{-1}$ to $100 \mathrm{~s}^{-1}$ were recorded at $25^{\circ} \mathrm{C}$ using an Advanced Peltier System for temperature control. A Biolin Scientific Attension Theta contact angle measurement system was used to measure the contact angles of the ink on different substrates. A Scintag PAD x-ray diffractometer operating at $40 \mathrm{kV}$ was used to investigate the crystal structure of BST nanoparticles. A JEOL JEM-2100 transmission electron microscope operating at $200 \mathrm{keV}$ was used to obtain both conventional and high-resolution transmission electron microscopy (HRTEM) images of BST nanoparticles. A Zeiss Auriga focused ion beam scanning electron microscope (FIB) operating at 5 $\mathrm{keV}$ was used to investigate the surface morphology and the cross sections of printed features. A gallium liquid metal ion source at $30 \mathrm{kV}$ and $50 \mathrm{pA}$ was used for FIB milling. An Agilent Cary 8454 ultraviolet/visible/near-infrared (UV/ Vis/NIR) spectrophotometer was used for UV-Vis absorption measurements of liquid ink. A Keyence VHX-5000 digital microscope was used for the initial investigation of cracks after the curing. Also, a $1000 \times$ lens was used for $3 \mathrm{D}$ stitching to investigate the surface roughness and the step heights of printed features. A VTC-50 desktop spin coater was used to prepare spin-coated BST films for tunability measurements. A Keysight N5225A PNA microwave network analyzer $(50 \mathrm{GHz})$ was used to collect the S11 reflection coefficients of the BST ink-filled test devices. Fully printed concentric cylindrical capacitors were used as the test devices. Picoprobe model 40A ground-signal-ground (GSG) RF probes with an $800-\mu \mathrm{m}$ pitch were used to probe the test devices from $2 \mathrm{GHz}$ to $12 \mathrm{GHz}$. An MPI TS2000-SE probe station with an ERS temperature chuck was used to collect the temperature-dependent S11 reflection coefficients of the BST ink-filled test devices.

\section{Extraction Method of Dielectric Properties of BST Nanoparticle Ink}

Fully printed concentric cylindrical capacitors on Kapton substrates with a 200- $\mu \mathrm{m}$ gap were used as the device under test (DUT) (Figs. S1 and S2) for the extraction of the dielectric constant and the loss tangent. ${ }^{5,45}$ Paru MicroPE PG-007 silver ink was used in the Optomec AJ200 aerosol jet printer to print the DUT. The printed DUT was cured/ sintered at $250^{\circ} \mathrm{C}$ for $3 \mathrm{~h}$ in a vacuum oven. The BST ink was filled into the gap of the DUT using the Nordson automatic dispensing system and cured according to the specification mentioned in "BST Ink Formulation, Printing and Curing Procedure" section. The height of the DUT was measured using the 3D profiles obtained from the Keyence VHX-5000 digital microscope before and after the BST filling to calculate the accurate height of the BST filling. S11 reflection coefficients of the DUT were collected before and after the
BST filling and the dielectric constant and the loss tangent were extracted. The detailed extraction method can be found in the supporting information section.

BST layers of around 10-30 $\mu \mathrm{m}$ were spin coated on copper substrates, and then concentric cylindrical capacitors with 200- $\mu \mathrm{m}$ gaps were printed on these BST layers (Fig. S3) to extract the dielectric tunability of BST ink. S11 reflection coefficients were collected at different applied electric field strengths up to $10 \mathrm{~V} / \mu \mathrm{m}$. The detailed extraction method can be found in the supporting information section. Moreover, temperature-dependent $\mathrm{S} 11$ reflection coefficients were collected from $-50^{\circ} \mathrm{C}$ to $125^{\circ} \mathrm{C}$ in order to extract the dielectric constants and the loss tangents at different temperatures to determine the variability of the dielectric properties with respect to temperature.

\section{Results and Discussion}

\section{X-ray Diffraction Patterns and TEM/HRTEM Images of BST Nanoparticles}

X-ray diffraction (XRD) patterns confirmed the singlephase cubic structure of BST nanoparticles (Fig. 1a), which confirmed the para-electric phase (nonpolar phase) of BST nanoparticles at room temperature. ${ }^{27}$ The calculated lattice constant using the XRD data was $a=3.97 \AA$, which is consistent with previous reports. ${ }^{28}$ In order to achieve the dielectric tunability of BST nanoparticles under an applied electric field, BST nanoparticles must be in the para-electric phase. ${ }^{27}$ Figure $1 \mathrm{~b}$ shows the TEM image of BST nanoparticles in the BST dispersion (stock solution), and the average size of the nanoparticles is around $80 \mathrm{~nm}$. The HRTEM image in Fig. 1c shows the atomic planes corresponding to BST (110) planes. The measured $d$-spacing is $2.81 \AA$, which is consistent with XRD results and closely matches previous reports. $^{12,15}$

\section{Composition of the BST Nanoparticle Ink}

In order to achieve the dielectric tunability, it is necessary to have the para-electric phase of BST nanoparticles at room temperature. ${ }^{27}$ Therefore, the Ba molar faction was set to 0.67 according to previous work. ${ }^{28}$ Detailed information about the variation of the Ba molar fraction and the operational temperature range of the para-electric phase of BST nanoparticles can be found elsewhere. ${ }^{28}$

Table I shows the composition of the BST nanoparticle ink. Spherical BST nanoparticles with $\mathrm{Ba} / \mathrm{Sr}=67: 33$ were used as the main functional material. ${ }^{28}$ Ammonium polymethacrylate was used as the dispersant to disperse BST nanoparticles in ethylene glycol, which was used as the stock solution for the BST nanoparticle ink. The BST nanoparticle 
(a)

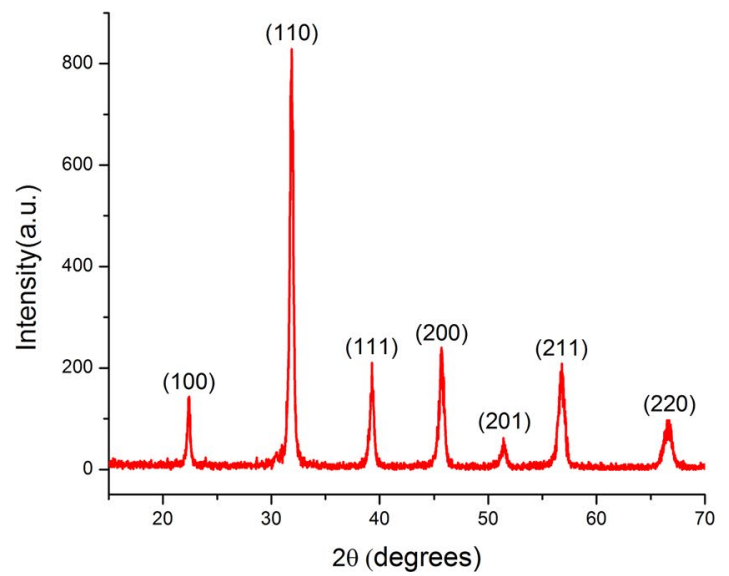

(b)

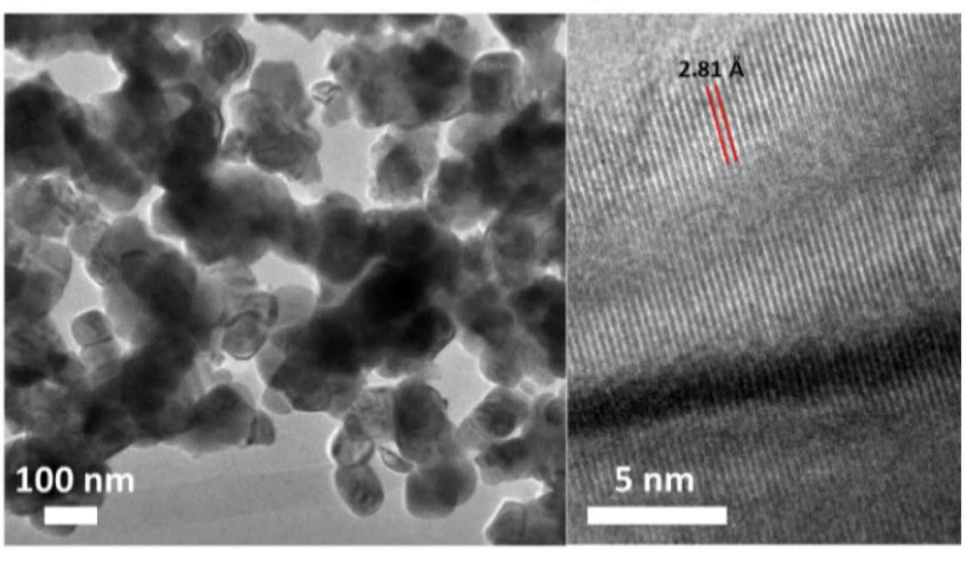

Fig. 1. (a) X-ray diffraction pattern of BST nanoparticles. (a) TEM image, (b) HRTEM image of BST nanoparticles.

Table I. BST nanoparticle ink composition

\begin{tabular}{ll}
\hline Ink component & $\begin{array}{l}\text { Weight } \\
\text { percentage } \\
(\%)\end{array}$ \\
\hline BST nanoparticles & 34.0 \\
Ethylene glycol & 48.7 \\
1-Methoxy-2-propanol & 16.0 \\
Ammonium polymethacrylate & 1.3 \\
\hline
\end{tabular}

dispersion was highly stable for over 1 year in the refrigerator. The high boiling point, dynamic viscosity of around 15 $\mathrm{cP}$ at room temperature and the solvent compatibility (with mostly used solvents for ink formulations) of ethylene glycol provide more freedom for different ink formulations. ${ }^{46}$ These are the main reasons for using ethylene glycol as the main solvent in this work. 1-Methoxy-2-propanol was used as the secondary solvent, which has a lower boiling point compared to ethylene glycol and forms a miscible solution with ethylene glycol. The relatively high vapor pressure of 1-methooxy-2-propanol increases the drying rate, which in turn will decrease the curing temperature. ${ }^{47-49}$ The lower curing temperature allows this ink to be used in a wide range of low-temperature flexible substrates. Also, the faster drying rate helps to remove most of the solvents right after the deposition by increasing the platen temperature of the printer. This will allow printing of multiple layers continuously without curing each layer. In addition to that, 1-methoxy-2-propanol improves aerosol generation, and most of it will evaporate during the deposition. Therefore, the contribution of 1-methoxy-2-propanol to the wet thickness of printed features is minimal. Less solvent contribution to the wet thickness always helps to minimize the cracking and the coffee ring effect during the curing of printed films. BST

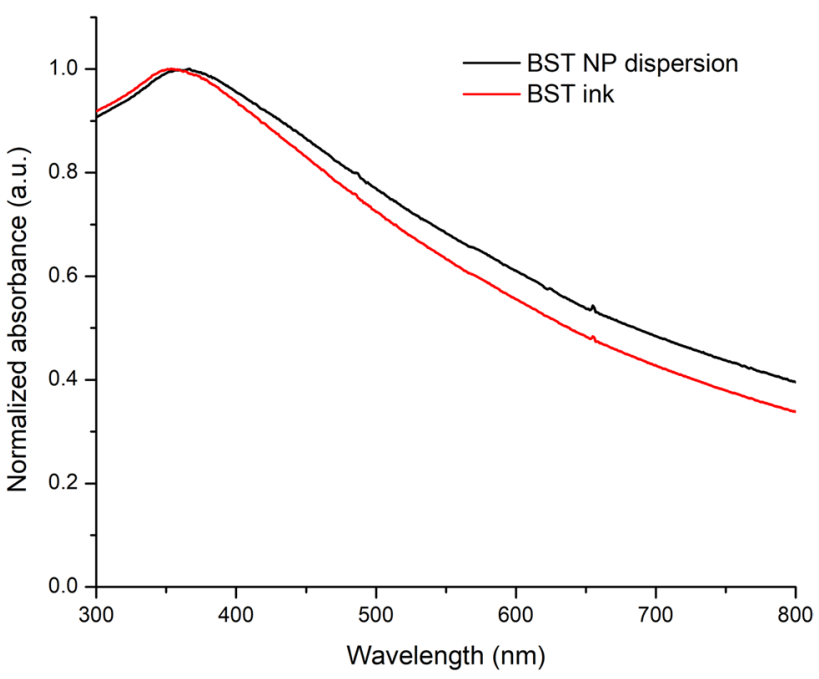

Fig. 2. UV-Vis absorption spectra of BST nanoparticle dispersion (black) and BST ink (red) (Color figure online).

nanoparticles of the ink (after the curing) were randomly packed, and there were air gaps between BST nanoparticles.

\section{UV-Vis Absorption Spectra of the BST Nanoparticle Dispersion and the BST Nanoparticle Ink}

Figure 2 shows the UV-Vis absorption spectra of the BST nanoparticle dispersion and the BST ink. The broader absorption peak around $366 \mathrm{~nm}$ can be assigned to the bandgap absorption of BST nanoparticles in the BST nanoparticle dispersion. The absorption peak of the BST ink is around $354 \mathrm{~nm}$, which is slightly blueshifted compared to the BST nanoparticle dispersion. The blueshift of the peak can be attributed to the breaking down of the agglomerated BST nanoparticles in the BST ink due to the additional solvent, 
1-methoxy-2-propanol. Agglomerated BST nanoparticles of the BST nanoparticle dispersion can also be seen in the TEM image in Fig. $1 b$.

\section{Viscosity and Contact Angles of the BST Nanoparticle Dispersion and the BST Nanoparticle Ink}

Figure 3 shows the dynamic viscosity variation with the shear rate up to $100 \mathrm{~s}^{-1}$ for the BST nanoparticle dispersion and the BST ink. BST nanoparticle dispersion shows a strong shear thinning behavior mostly due to the dissociation and the settling of agglomerated BST nanoparticle clusters. The viscosity of the BST nanoparticle dispersion dropped by $94 \%$ from $1.00 \mathrm{~s}^{-1}$ to $100 \mathrm{~s}^{-1}$. However, the BST ink only showed a $13 \%$ drop in viscosity in the same range of shear rates, and that can be attributed to the breakdown of most of the agglomerated BST nanoparticle clusters due to the secondary solvent, 1-methoxy-2-propanol. The Newtonian behavior of the viscosity over the range of shear rates is an indication of a stable ink for high-shear jetting, such as inkjet printing. ${ }^{50}$ In aerosol jet printing, inks will not experience very high shearing, but in inkjet printing, inks will experience very high shearing near the nozzle. The viscosity of the BST ink was around $22.5 \mathrm{cP}$ at a $1.00-\mathrm{s}^{-1}$ shear rate, which is in the range of viscosities that can be printed using pneumatic atomizers in aerosol jet printers as well as most of the inkjet printers.

Table II shows the contact angles of the ink on different substrates that are suitable for high-frequency applications. The contact angle of the BST ink was smaller than $90^{\circ}$ for all the tested substrates, and it confirmed the good wettability of the ink. The optical images of the contact

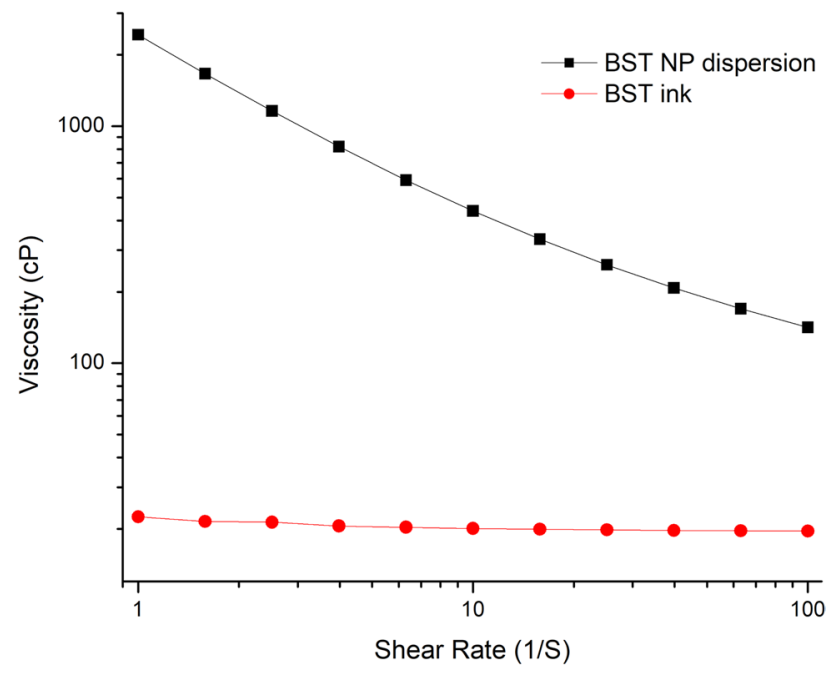

Fig. 3. Viscosity vs. shear rate graphs for the BST nanoparticle dispersion (black) and the BST ink (red) (Color figure online).
Table II. Contact angles of BST nanoparticle inks on different substrates

\begin{tabular}{ll}
\hline Substrate & $\begin{array}{l}\text { Contact } \\
\text { angle }\left(^{\circ}\right)\end{array}$ \\
\hline Kapton & 29.3 \\
LCP & 38.7 \\
RO3035 & 47.6 \\
RO5870 & 74.2 \\
$\begin{array}{l}\text { Polyethylene tereph- } \\
\text { thalate (PET) }\end{array}$ & 34.3 \\
Copper & 64.5 \\
\hline
\end{tabular}

angles on different substrates can be found in Fig. S4. Even though the smaller contact angles show a higher wettability, it is necessary to have a moderate contact angle to control the dimensions of the printed features with high precision.

\section{Printing and Curing of the BST Nanoparticle Ink}

BST ink was printed in Optomec AJ200 and AJ5X aerosol jet printers with a pneumatic atomizer. Flow rates of 650 $\mathrm{cm}^{3} / \mathrm{min}, 640 \mathrm{~cm}^{3} / \mathrm{min}$ and $50 \mathrm{~cm}^{3} / \mathrm{min}$ were used for the pneumatic atomizer, the exhaust and the sheath gas, respectively. The flow rates were optimized to achieve high-quality printed lines with minimum overspraying. The deposited volume of the ink mainly depends on the difference between the flow rates of the pneumatic atomizer and the exhaust. The sheath gas flow rate was mainly used to adjust the line width; the higher the sheath gas, the lower the line width. The smallest line width achieved was around $100 \mu \mathrm{m}$ with a $300-\mu \mathrm{m}$ tip. If necessary, a smaller tip size $(100 \mu \mathrm{m}$ or 150 $\mu \mathrm{m})$ can be used to achieve smaller features $(\sim 20 \mu \mathrm{m}$ to 30 $\mu \mathrm{m})$. The printing speed was $10 \mathrm{~mm} / \mathrm{s}$, and the thickness of one layer was around $4 \mu \mathrm{m}$. The plate was heated up to $70^{\circ} \mathrm{C}$, and it helped to evaporate most of the solvents during the printing, which allowed the continuous printing of multiple layers without the complete curing of printed samples. Seven layers were printed continuously with the above printing parameters, and the layer thickness was close to $30 \mu \mathrm{m}$.

The curing temperature is critical for most of the printed electronics applications due to the low melting point of flexible substrates. ${ }^{51,52}$ The curing temperature of the ink in this study was $150^{\circ} \mathrm{C}$ for $60 \mathrm{~min}$ in a vacuum oven. Much of the previous work done with sintered BST nanoparticles used very high processing temperatures. According to the author's knowledge, no work has been reported on a BST ink that could be cured below $150^{\circ} \mathrm{C}$. The closest reported lowcuring BST ink was a BST/cyclic olefincopolymer (COC) nanocomposite ink, which was cured at $200^{\circ} \mathrm{C} .{ }^{5}$ The BST ink was stable when continuously printed for a few hours without clogging the aerosol jet printers. 


\section{Surface and Cross-Sectional SEM Images of the BST Nanoparticle Ink}

Figure $4 \mathrm{a}$ and $\mathrm{b}$ show the SEM images of the surface and the cross section of the cured BST ink, respectively. After the curing, the printed feature only has randomly packed pure BST nanoparticles with air-filled pores that can be seen in Fig. 4b. The individual BST nanoparticles are around 80 $\mathrm{nm}$, but agglomerated nanoparticles (nanoclusters) on the order of $1 \mu \mathrm{m}$ were identified using both surface and crosssectional SEM images. These agglomerated nanoparticles decrease the packing density, which creates air-filled pores. The air-filled pores will decrease the effective dielectric constant of the printed BST feature. As a result, the solid density of the final cured BST device is relatively low compared to sintered BST devices. Therefore, a high dielectric constant that is similar to sintered BST devices cannot be expected. Integrating a filler material is the best solution to fill the pores, which will help to increase the effective dielectric constant after the curing. However, introducing polymer materials into the aerosol jet inks is challenging due to difficulties in dissolving polymers in aerosol jet inkcompatible solvents, inefficient aerosol generation, and tip clogging. Even though the characterization of pores is not the goal of this work, several investigations are underway in parallel to this work to decrease the pore density to increase the effective dielectric constant.

\section{Dielectric Properties of the BST Nanoparticle Ink}

The dielectric constant and the loss tangent of the BST ink were extracted between $2 \mathrm{GHz}$ and $12 \mathrm{GHz}$. The details of the extraction procedure can be found in the supporting information section. Figure 5a shows the variation of the dielectric constant from $2 \mathrm{GHz}$ to $12 \mathrm{GHz}$. A table of dielectric constants and loss tangents at $10 \mathrm{GHz}$ can be found in the Supplementary Information (Table S1). The dielectric constant of the cured BST ink did not show a large variation throughout the tested frequency range. The extracted dielectric constant and loss tangent were $16.13 \pm 0.71$ and $0.06 \pm 0.01$ at $10 \mathrm{GHz}$, respectively.

Figure $5 \mathrm{~b}$ shows the dielectric tunability vs. the applied electric field strength for the BST ink. The highest tunability of around $\sim 15 \%$ was achieved at $10 \mathrm{GHz}$ with the applied electric field strength of $10 \mathrm{~V} / \mu \mathrm{m}$. This value for tunability is the highest that has been reported for non-sintered BST at $10 \mathrm{GHz}$. The tunability calculation method can be found in the supporting information ("Results and Discussion" section). The para-electric phase of the BST crystal lattice has a symmetric cubic structure, and the Ti atom is located in the center of the unit cell. ${ }^{27}$ Under an applied external electric field, the Ti atom could get shifted away from the equilibrium position. ${ }^{27}$ The Ti atom would continue to oscillate, but with less intensity, which will decrease the dielectric constant. ${ }^{27}$ The capacitance between the middle circular part of the DUT and the ground plane was used to calculate the tunability. At the device level, reversible tunability is very important to make a reliable device. The reversible tunability was tested by increasing and decreasing the applied electric field strength. In both directions, BST ink showed a very consistent tunability (Fig. S5).

There are some potential applications in space and harsh weather for BST-based tunable devices, which require thermal stability over a broad range of temperatures. Figure 6 shows the variations of the dielectric constant and the loss tangent at $10 \mathrm{GHz}$ from $-50^{\circ} \mathrm{C}$ to $125^{\circ} \mathrm{C}$ for the BST ink. The temperature of the chuck of the probe station was adjusted, and after the temperature was stabilized, S11 parameters were measured in order to extract the dielectric constant in the same way as mentioned in "Extraction Method of Dielectric Properties of BSTNanoparticle Ink" section. The maximum variation of the dielectric constant between $-50^{\circ} \mathrm{C}$ and $125^{\circ} \mathrm{C}$ was $\sim 10 \%$. The loss tangent increased at lower and higher temperatures compared to
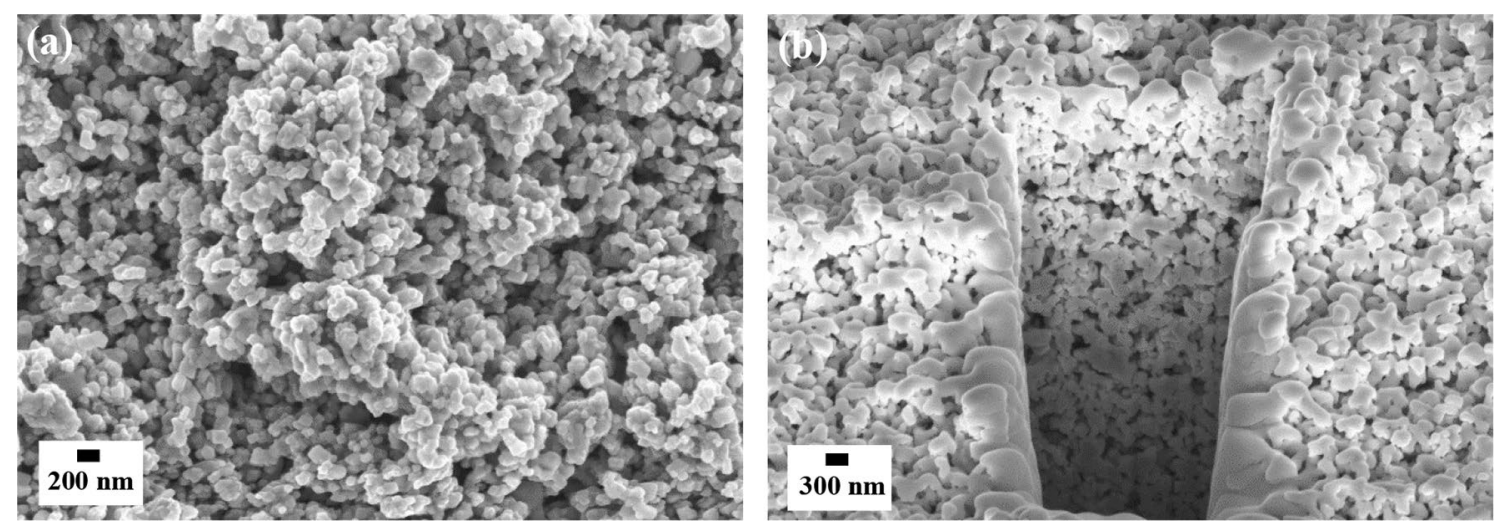

Fig. 4. (a) Surface SEM image and the (b) cross-sectional SEM image of the cured BST ink. 

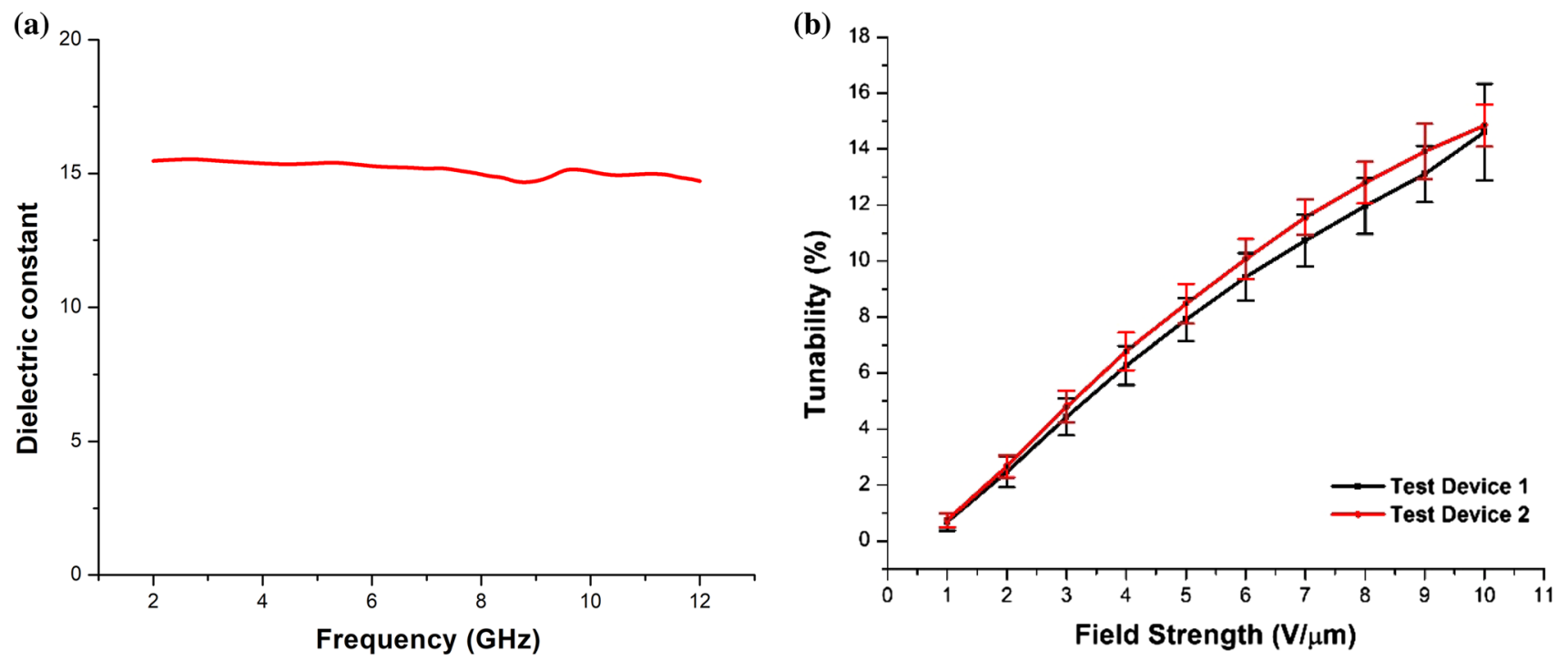

Fig. 5. (a) The variation of the dielectric constant between $2 \mathrm{GHz}$ and $12 \mathrm{GHz}$. (b) Dielectric tunability at $10 \mathrm{GHz}$ under different applied electric field strengths (Color figure online).

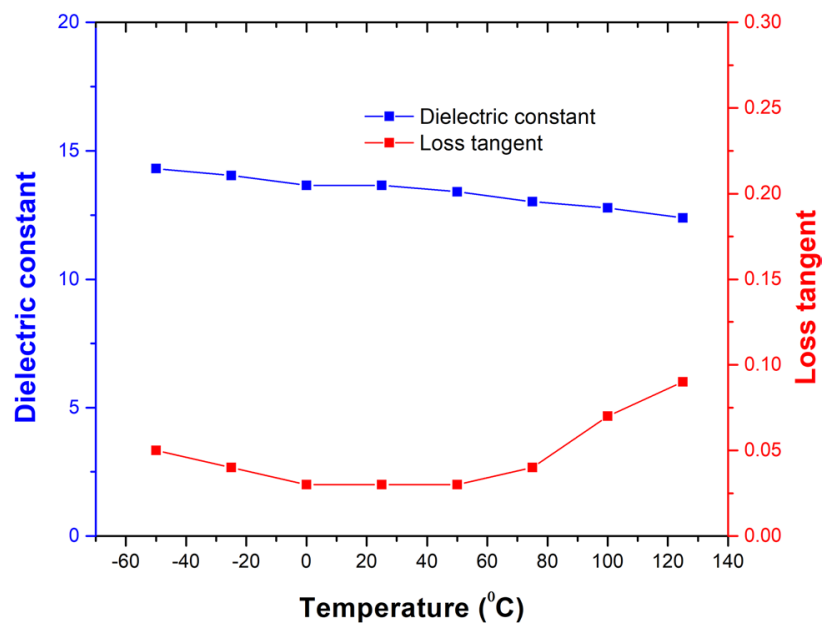

Fig. 6. The variation of (a) dielectric constant and (b) loss tangent from $-50^{\circ} \mathrm{C}$ to $125^{\circ} \mathrm{C}$ (Color figure online).

room temperature. The effects of structural changes of the printed silver DUT due to thermal expansion and contraction could be the possible reason for the extracted higher loss tangent at temperatures different from room temperature.

\section{Conclusion}

A sinterless BST nanoparticle ink was formulated and characterized for aerosol jet printers. There are no previously reported sinterless BST nanoparticle inks that use low processing temperatures $\left(<150^{\circ} \mathrm{C}\right)$ and have good printing performance with similar or higher dielectric properties between the
2-GHz and 12-GHz frequency region. The dielectric constant, the loss tangent and tunability showed reproducible results, which would allow this BST nanoparticle ink to be used in printed radio-frequency and microwave applications. The maximum tunability of $\sim 15 \%$ at $10 \mathrm{GHz}$ was obtained with the applied electric field strength of $10 \mathrm{~V} / \mu \mathrm{m}$. The maximum dielectric constant variation (at $10 \mathrm{GHz}$ ) between $-50^{\circ} \mathrm{C}$ and $125^{\circ} \mathrm{C}$ was around $10 \%$. The BST ink was tested on several flexible and rigid substrates, and the ink was compatible with a wide range of tested substrates. This BST ink was formulated and optimized for aerosol jet printers, but it is not limited to aerosol jet printing technology. The ink could be easily modified for other printing techniques, such as inkjet, screen printing, gravure and flexographic printing technologies.

Supplementary Information The online version contains supplementary material available at https://doi.org/10.1007/s11664-021-08915-7.

Acknowledgments The authors would like to thank Raytheon Technologies for funding this project. The authors also would like to thank students, staff and faculty members at Printed Electronics Research Collaborative (PERC) and Raytheon UMass Lowell Research Institute (RURI) of the University of Massachusetts Lowell, USA, for their support.

Conflict of interest The authors declare that they have no conflict of interest.

\section{References}

1. A. Tombak, J. Maria, F. Ayguavives, J. Zhang, G.T. Stauf, A.I. Kingon, and A. Mortazawi, IEEE Microw. Wirel. Compon. Lett. 12,3 (2002). 
2. M. Haghzadeh, and A. Akyurtlu, J. Appl. Phys. 120, 184901 (2016).

3. M. Haghzadeh, C. Armiento, and A. Akyurtlu, IEEE Trans. Microw. Theory Tech. 65, 2030 (2017).

4. M. Haghzadeh, L. M. Bhowmik, C. Armiento, and A. Akyurtlu, in 2014 USNC-URSI Radio Science Meeting (Joint with AP-S Symposium), pp. 154 (2014).

5. M. Haghzadeh, C. Armiento, and A. Akyurtlu, in 2016 IEEE MTT-S International Microwave Symposium (IMS), p. 1. (2016)

6. H. Wang, Y. Dong, and Z. Wang, J. Alloys Compd. 745, 651 (2018).

7. M. Mikolajek, A. Friederich, C. Kohler, M. Rosen, A. Rathjen, K. Krüger, and J.R. Binder, Adv. Eng. Mater. 17, 1294 (2015).

8. B. Hou, Y. Xu, D. Wu, and Y. Sun, Powder Technol. 170, 26 (2006).

9. D. Dong, X. Liu, H. Yu, and W. Hu, Ceram. Int. 37, 579 (2011).

10. L. Huang, Z. Jia, I. Kymissis, and S. O'Brien, Adv. Funct. Mater. 20, 554 (2010).

11. V. Somani, and S.J. Kalita, J. Electroceram. 18, 57 (2007).

12. C.W. Beier, M.A. Cuevas, and R.L. Brutchey, J. Mater. Chem. 20, 5074 (2010).

13. E. Yustanti, M.A.E. Hafizah, and A. Manaf, AIP Conf. Proc. 1725 , 020102 (2016).

14. S. Yang, B.R. Tull, N.K. Pervez, L. Huang, E.S. Leland, D.A. Steigart, S. O'Brien, and I. Kymissis, J. Polym. Sci. Part B Polym. Phys. 51, 35 (2013).

15. C.W. Beier, J.M. Sanders, and R.L. Brutchey, J. Phys. Chem. C 117, 6958 (2013).

16. F.A. Rabuffetti, J.S. Lee, and R.L. Brutchey, Chem. Mater. 24, 3114 (2012).

17. S. Ketkar, Synthesis, Characterization and Applications of Barium Strontium Titanate Thin Film Structures (2013).

18. S. Liu, S. Xue, W. Zhang, J. Zhai, and G. Chen, J. Mater. Chem. A 2, 18040 (2014).

19. T. Ikeda, S. Saito, and Y. Kimura, in 2018 IEEE International Symposium on Antennas and Propagation \& USNC/URSI National Radio Science Meeting, pp. 279 (2018).

20. S.P. Bruss, and R.R. Spencer, IEEE Microw. Wirel. Compon. Lett. 19, 596 (2009).

21. M. Nikfalazar, C. Kohler, A. Wiens, A. Mehmood, M. Sohrabi, H. Maune, J.R. Binder, and R. Jakoby, IEEE Microw. Wirel. Compon. Lett. 26, 70 (2016).

22. M. Nikfalazar, M. Sazegar, A. Mehmood, A. Wiens, A. Friederich, H. Maune, J.R. Binder, and R. Jakoby, IEEE Antennas Wirel. Propag. Lett. 16, 585 (2017).

23. L. Ma, F. Meng, X. Liu, and P. Wang, in Proceedings of 2014 3rd AsiaPacific Conference on Antennas and Propagation, pp. 1389 (2014).

24. G. Velu, K. Blary, L. Burgnies, A. Marteau, G. Houzet, D. Lippens, and J. Carru, IEEE Trans. Microw. Theory Tech. 55, 438 (2007).

25. V. Sanchez-Romaguera et al., J. Mater. Chem. C 3, 2132 (2015).

26. M. Kunduraci, W. K. Simon, E. K. Akdogan, and A. Safari, in 14th IEEE International Symposium on Applications of Ferroelectrics, 2004. ISAF-04. 2004, pp. 21 (2004).
27. S. Gevorgian, Ferroelectrics in Microwave Devices, Circuits and Systems: Physics, Modeling, Fabrication and Measurements, , p. 21 (London: Springer, 2009).

28. M. Haghzadeh, University of Massachusetts Lowell (2016).

29. Y.C. Teh, N.R. Ong, Z. Sauli, J.B. Alcain, and V. Retnasamy, AIP Conf. Proc. 1885, 020290 (2017).

30. F.W. Jamaluddin, M.F. Khalid, M.H. Mamat, and A.S. Zoolfakar, in 2017 IEEE 13th Malaysia International Conference on Communications (MICC), pp. 63 (2017).

31. A. Kumar, S.G. Manavalan, V. Gurumurthy, S. Jeedigunta, and T. Weller, Mater. Sci. Eng. B 139, 177 (2007).

32. V. Craciun, and R.K. Singh, Appl. Phys. Lett. 76, 1932 (2000).

33. J.-H. Lee, and S.-W. Rhee, J. Mater. Res. 14, 3988 (1999).

34. L. Zhang, J. Wu, M.N. Hedhili, X. Yang, and P. Wang, Journal of Materials Chemistry A 3, 2844 (2015).

35. E. Tekin, P.J. Smith, and U.S. Schubert, Soft Matter 4, 703 (2008).

36. F. Hoeng, J. Bras, E. Gicquel, G. Krosnicki, and A. Denneulin, RSC Adv. 7, 15372 (2017).

37. A. Teichler, J. Perelaer, and U.S. Schubert, J. Mater. Chem. C 1, 1910 (2013).

38. C. Sturgess, C.J. Tuck, I.A. Ashcroft, and R.D. Wildman, J. Mater. Chem. C 5, 9733 (2017).

39. F.-X. Wang, J. Lin, W.-B. Gu, Y.-Q. Liu, H.-D. Wu, and G.-B. Pan, Chem. Commun. 49, 2433 (2013).

40. J. Zhao, Y. Gao, W. Gu, C. Wang, J. Lin, Z. Chen, and Z. Cui, J. Mater. Chem. 22, 20747 (2012).

41. Y. Aleeva, and B. Pignataro, J. Mater. Chem. C 2, 6436 (2014).

42. K. Ankireddy, S. Vunnam, J. Kellar, and W. Cross, J. Mater. Chem. C 1, 572 (2013).

43. J.M. Meruga, A. Baride, W. Cross, J.J. Kellar, and P.S. May, J. Mater. Chem. C 2, 2221 (2014).

44. S. Wünscher, R. Abbel, J. Perelaer, and U.S. Schubert, J. Mater. Chem. C 2, 10232 (2014).

45. E. Harper, M. Haghzadeh, E. Hajisaeid, C. Armiento, and A. Akyurtlu, in 2017 89th ARFTG Microwave Measurement Conference (ARFTG) (2017), pp. 1.

46. F.S. Jerome, J.T. Tseng, and L.T. Fan, J. Chem. Eng. Data 13, 496 (1968).

47. J. Varghese, K.P. Surendran, and M.T. Sebastian, $R S C A d v .4$, 47701 (2014).

48. J. Varghese, M. Teirikangas, J. Puustinen, H. Jantunen, and M.T Sebastian, J. Mater. Chem. C 3, 9240 (2015).

49. N. Joseph, J. Varghese, and M.T. Sebastian, J. Mater. Chem. C 4, 999 (2016).

50. X. Wang, W.W. Carr, D.G. Bucknall, and J.F. Morris, Rev. Sci. Instrum. 81, 065106 (2010).

51. I. Bretos, R. Jiménez, J. Ricote, and M.L. Calzada, Chem. Soc. Rev. 47, 291 (2018).

52. Q.-H. Lu, and F. Zheng, Advanced Polyimide Materials. ed. S.-Y. Yang (Amsterdam: Elsevier, 2018), p. 195.

Publisher's Note Springer Nature remains neutral with regard to jurisdictional claims in published maps and institutional affiliations. 